\title{
DIGITALCOMMONS
}

11-1-2005

\section{Statistical Pronouncements IV}

JMASM Editors

Follow this and additional works at: http://digitalcommons.wayne.edu/jmasm

Part of the Applied Statistics Commons, Social and Behavioral Sciences Commons, and the Statistical Theory Commons

\section{Recommended Citation}

Editors, JMASM (2005) "Statistical Pronouncements IV," Journal of Modern Applied Statistical Methods: Vol. 4 : Iss. 2 , Article 30. DOI: $10.22237 /$ jmasm/1130804940

Available at: http://digitalcommons.wayne.edu/jmasm/vol4/iss2/30 


\section{Statistical Pronouncements IV}

"By sampling, we can learn only about collective properties of populations, not about the properties of individuals" - William G. Cochran, Frederick Mosteller, \& John W. Tukey (1954, Principles of sampling, Journal of the American Statistical Association, 49, p. 17).

"If a student has not already at least some facility with graphs and logarithms then he is, I believe, ill-advised to start to grapple with the theory of statistics" - Bernard L. Welch, (1954, Book Reviews, Journal of the American Statistical Association, 49, p. 378).

"Type, paper, and binding are good" - H. W. Norton (1954, Book Reviews, Journal of the American Statistical Association, 49, p. 390).

"It is curious that there are many people who are established scientists, and many others offering to become scientists, who have so little mathematics" - H. W. Norton (1954, Book Reviews, Journal of the American Statistical Association, 49, p. 390).

"Choice of subject matter is always an author's prerogative" - J. H. Curtiss, (1954, Book Reviews, Journal of the American Statistical Association, 49, p. 401).

"Once upon a time the calculation of the first four moments was an honorable art in statistics" - John W. Tukey (1954, Unsolved problems of experimental statistics, Journal of the American Statistical Association, 49, p. 717).

"Why isn't someone writing a book on one- and two-sample techniques? (After all, there is a book being written on the straight line!" - John W. Tukey (ibid, p. 721).

"With this issue, the Journal will discontinue publication of random digits" - (1954, RANDOM DIGITS (20,876-21,875), Journal of the American Statistical Association, 49, p. 928).
"At a Galton Laboratory tea in 1937, when there were few text books to guide a student in study of statistical methods for research, Fisher remarked that the way to obtain a good one would be for everyone who might feel the urge to try his hand and see which product would survive... The flood is now upon us" $-\mathrm{H}$. Fairfield Smith, (1955, Book Reviews, Journal of the American Statistical Association, 50, p. 975).

"If told another elementary text is to be written, my reaction is: Please, not another!" - $\mathrm{H}$. Fairfield Smith, (1955, Book Reviews, Journal of the American Statistical Association, 50, p. 979).

"Leonard J. Savage recommended us to read about the foundations of statistics sitting bolt upright on a hard chair, at a desk, and now [Michel] Loève asks us to approach his monumental treatise on the foundations of probability theory "armed permanently with patience, pebble, and reed" - Walter L. Smith, (1955, Book Reviews, Journal of the American Statistical Association, 50, p. 986).

"This is by far the largest and best collection of random digits yet" - W. Allen Wallis (1955, Book Reviews, Journal of the American Statistical Association, 50, p. 987)

"Good examples in theoretical statistics are not easy to find" - Herman Chernoff (1955, Book Reviews, Journal of the American Statistical Association, 50, p. 1334).

"The naive reader is almost certain to form a set of incorrect ideas concerning inference about distribution means. He is likely to feel that the assumption of normality of distribution is about on the same level as the use of a sharp pencil nice but not exactly necessary" - Leo Katz (1955, Book Reviews, Journal of the American Statistical Association, 50, p. 1344). 
"The practitioner of statistical inferences must understand much more of his art than he brings to bear on a specific problem; therefore, the 'cookbook' approach cannot succeed" - Leo Katz (ibid, p. 1344).

"I never knew a statistician who thought he knew enough mathematics" - Leonard J. Savage (1955, Book Reviews, Journal of the American Statistical Association, 50, p. 1352).

"Nondeductive reasoning is of paramount importance to the statistician" - Leonard J. Savage (ibid, p. 1352).

"The statistician like the scientist has to be concerned primarily with the collection and arrangement of and the reasonable inferences from observed data. Some mathematics will surely help, too much will surely hinder" Edwin B. Wilson (1955, Book Reviews, Journal of the American Statistical Association, 50, p. 1356).

"Using $\mathrm{P}=.05$ [is] all right if understood, but the businessman, the investor, the weather forecaster, the executive, or the card player who waited for that degree of significance would be so out of the game as to be without a livelihood" - Edwin B. Wilson (ibid, p. 1357).

"Science is always provisional and usually approximately, and thus constantly being corrected" - Edwin B. Wilson (ibid, p. 1357).

"Every statistician knows something about stochastic processes, though like me he may be late to learn, and never entirely comfortable with, that awesome sounding name - Leonard J. Savage (1956, Book Reviews, Journal of the American Statistical Association, 51, p. 383)

"The best philosophers are often mathematicians" - - I. J. Good (1956, Book Reviews, Journal of the American Statistical Association, 51, p. 388).
"Decision theory is not a subject that can be appreciated in all its austere details by a statistician with less than one or two years of experience of real life" - I. J. Good (1956, Book Reviews, Journal of the American Statistical Association, 51, p. 388).

"To all of us some of the time and to some of us all of the time it seems that economics fails to make progress as other sciences do" - Robert M. Solow (1956, Book Reviews, Journal of the American Statistical Association, 51, p. 398).

"1955 saw the creation of a new Committee to Investigate Statistics as Evidence. The Committee, under the chairmanship of John Tukey, was appointed in response to recommendations based on the fact that many lawyers fail to recognize the validity of statistics as evidence" - American Statistical Association (1956, Report of the board of directors, 1955, Journal of the American Statistical Association, 51, p. 424).

"Much oh!ing and ah!ing has been heard in the land about those prodigious giants, the new electronic computing machines" - Thornton C. Fry (1956, The automatic computer in industry, Journal of the American Statistical Association, 51, p. 565).

"The theory of decision making, the natural sequel to hypothesis testing, has elevated the notion of risk to an even higher place in the hierarchy of ideas passed on from professor to student" - A. W. Kimball (1957, Errors of the third kind in statistical consulting, Journal of the American Statistical Association, 52, p. 133).

"A scientist with ideas frames his hypotheses and wishes to test them" - E. J. G. Pitman (1957, Statistics and science, Journal of the American Statistical Association, 52, p. 323).

"Nonparametric methods are needed in many fields, and can be applied in all" - I. Richard Savage (1957, Nonparametric statistics, Journal of the American Statistical Association, 52, p. $331)$. 